\title{
Urgences
}

\section{Une nuit de New-Carlisle}

\section{Gilbert Dupuis}

Numéro 10, 2e trimestre 1984

Spécial fantasmes

URI : https://id.erudit.org/iderudit/025161ar

DOI : https://doi.org/10.7202/025161ar

Aller au sommaire du numéro

Éditeur(s)

Urgences

ISSN

0226-9554 (imprimé)

1927-3924 (numérique)

Découvrir la revue

Citer ce document

Dupuis, G. (1984). Une nuit de New-Carlisle. Urgences, (10), 103-110.

https://doi.org/10.7202/025161ar

Ce document est protégé par la loi sur le droit d'auteur. L'utilisation des services d'Érudit (y compris la reproduction) est assujettie à sa politique d'utilisation que vous pouvez consulter en ligne.

https://apropos.erudit.org/fr/usagers/politique-dutilisation/
Cet article est diffusé et préservé par Érudit.

Érudit est un consortium interuniversitaire sans but lucratif composé de l’Université de Montréal, l'Université Laval et l'Université du Québec à Montréal. Il a pour mission la promotion et la valorisation de la recherche. https://www.erudit.org/fr/ 


\section{GILBERT DUPUIS}

\section{Une nuit de New-Carlisle}




\section{UNE NUIT DE NEW-CARLISLE *}

Deux barges dormaient côte à côte, un grand filet remonté jusqu'à leur proue. La Baie des Chaleurs écumait, en allers et retours chuchotés, la plage de Paspébiac. Le ciel avait plein de trous étoilés et la lune roulait en éclaireur au-devant des gros nuages.

L'antenne de CHNC coupait verticalement l'Ouest de pointillés rouges.

Main dans la main, Prunelle et Raviluc goûtaient la solitude du quai. Parfois, I'un troublait le silence de la promenade pour faire jouir l'autre d'une singulière senteur marine ou du balancement d'un mât dans une flaque lunaire. Les deux jeunes gens longèrent les anciens magasins de Charles Robin et remontèrent l'asphalte jusqu'à la route nationale.

"Je te fais pas mal aux doigts?", s'inquiéta Raviluc conscient tout à coup qu'il étreignait avec plus de ferveur que d'habitude la main de son amie.

"Oh! non!" le rassura Prunelle lui serrant affectueusement le bras pour la marque d'attention.

Le trottoir coupait le foin à dix pieds de la route entre Paspébiac et New Carlisle. La brillance des phares d'autos baissait les yeux de Prunelle et Raviluc. Partout, le doux de la mer salait la soirée. Malgré leur feuillage percé de lampadaires, de grands peupliers guidaient le chemin du roi. Le coeur étrange et la tête fondue, la jeune femme et le jeune homme progressaient vers la coïncidence des instincts. Raviluc mit son bras autour des épaules de Prunelle qui abandonna sa tête sur sa poitrine. Ils dépassèrent enlacés le restaurant "Au coq tendre". L'ouest du village avait l'obscurité plus étanche et les jeunes gens voulurent en profiter.

"Je te serre pas trop fort?", se troubla encore Raviluc s'écartant un peu.

* Extrait d'un roman à paraître. 
- Bien non.. c'est une obsession... je suis bien..., murmura Prunelle regagnant les bras de l'homme.

- Tes cheveux sentent la jasminelle de printemps! conclut-il se penchant vers elle.

- Merci... mais je connais pas cette plante-là..., avoua-telle demi-souriante.

- Oh! c'est une fleur que j'ai inventée... la source de ton parfum particulier tout simplement...", confia-t-il à Prunelle.

Depuis longtemps la rumeur villageoise s'était tue et la nuit se préparait une nuit calme et tiède. Le jeune homme respirait toujours la chevelure de son amie comme s'il appréciait l'essence rare de la fleur imaginaire. Doucement Prunelle lui caressa la nuque et lui, se réjouit de la fièvre dans ses mains. Lentement elle l'attira à elle et ils trouvèrent leurs lèvres en même temps. Ils se goûtèrent sans hâte ni brusquerie. Le commerce des salives prospéra longtemps... ils occupaient le trottoir. Maintenant, une brise charriait l'odeur du foin et des pissenlits jusque dans la mer.

Raviluc sentit sous ses doigts les frissons courir dans le cou de Prunelle; elle le convainquit pourtant d'un certain sourire qu'elle n'avait pas le moindrement froid. "Je suis content, content que tu sois là!" dit-il. Toujours enlacés, le couple gagna davantage la noirceur et le silence. Un seul corps, un seul rythme avançant dans la Gaspésie. Sur la droite, se profila l'Anglican Church derrière un écran de peupliers. Les jeunes gens poussèrent une porte grillagée et furent bientôt sur le perron de la petite église de bois blanc. Des pierres tombales couvraient presque toute la cour gauche et arrière de l'humble bâtisse. Prunelle et Raviluc se regardèrent se sourirent et firent pivoter la grille dans ses gonds derrière eux.

Une allée de cailloux blancs partageait le cimetière en deux. La jeune fille enleva ses souliers et ses pieds foulèrent le gazon fraîchement coupé entre les blocs de granit. La nuit sentait bon et l'air gardait encore des vestiges de la chaleur du 


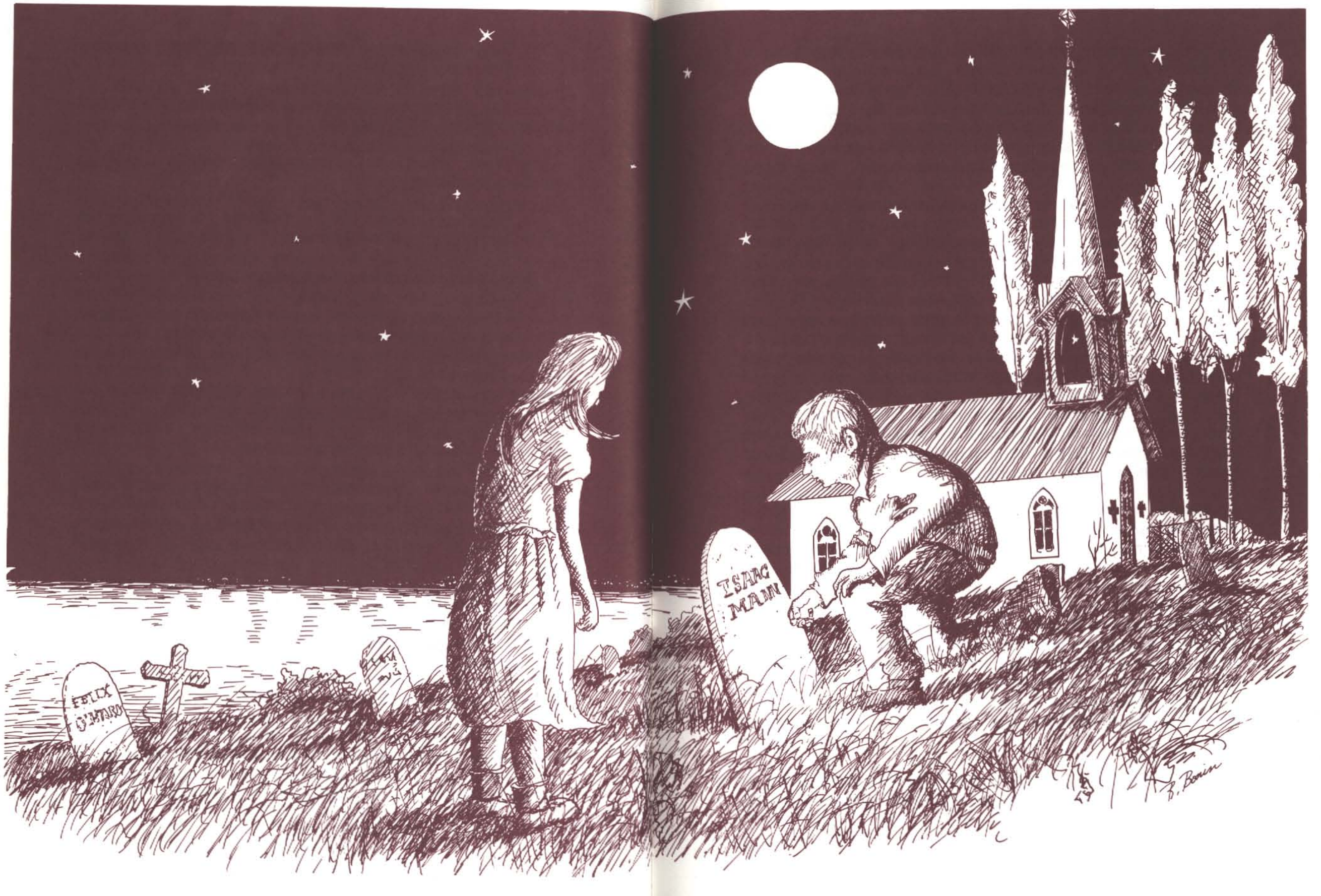


jour. À la lueur d'une allumette, Raviluc lut les noms gravés sur les pierres grises aux pieds de mousse avec le temps. Isaac Mann. Justus Sherwood. Félix O'Hara. John Gowler Thompson. Ella Finlay. Samuel Holland. John Flowers. Nicholas Cox. La flamme mourut et le jeune homme tomba dans I'herbe tiède. Les nuages faisaient apparaître puis disparaître la lune comme les magiciennes font des lapines.

Prunelle posa son sac contre un monument funéraire et vint s'allonger près de I'homme immobile au sol. Ils turent les paroles qu'ils savaient imparfaites d'avance. Se prirent plutôt la main, écoutèrent le silence se densifier de la musique des émotions. "Ça va?", s'enquit-elle d'une voix plus grave. II lui répondit par l'offrande de son avant-bras comme oreiller. Raviluc ferma les yeux. Couché sur la terre, le temps remontait mieux son cours... Ste-Olivine, l'école du rang, la maison de bardeaux chaulés, le drame, le feu. Chandler, la grande école, les exhalaisons souffrées du moulin. La métropole, le Mont Royal, le Parc Lafontaine, les G.I. Joe en boîtes à 70 cents I'heure, la parenté urbanisée jusque dans ses dimanches, les études vaille que vaille. Rimouski, la Société, le travail du feu toujours, Prunelle, la tendresse et le goût de marquer la terre d'une empreinte.

Raviluc se tourna vers la jeune femme et son sourire lui alluma la vue. II frôla sa joue de sa main brûlante. Prunelle colla ses lèvres contre ses tempes avec douceur et quelques précipitations. La poitrine du jeune homme connut une chaleur diffuse et sa tête de l'instant trouva la sérénité désabusée qu'il appelait. Raviluc lut une heureuse tension entre les paupières mi-closes de Prunelle. La terre exhalait des parfums de pissenlits, d'herbe et de rosée. Seuls la lune et le fanal électrique de la petite église troublaient les ténèbres. Ils s'embrassaient les lèvres et les yeux et les lèvres. Elle prenait sa tête dans ses mains, dessinait fébrile son visage. Ils se murmuraient des mystères, ils n'avaient pas envie de changer le silence.

Les doigts de Prunelle sous sa chemise firent Raviluc s'étirer comme un matou de printemps. II libéra sa main droite 
et suivit de très très près le corps de son amie.

Celle-ci se colla rondement contre lui et leur santé dut retrouver quelques couleurs. Raviluc, la respiration dans les cheveux de la jeune femme, lui disait: "Ah! que j'aime la jasminelle printanière!", pendant qu'il caressait son sein gauche son désir en émoi. Les yeux fermés, Prunelle voyageait dans son dos. Les phares d'une voiture allumèrent trois secondes la façade de I'Anglican Church.

II avait défait la blouse de Prunelle, elle avait ouvert sa chemise pour qu'ils marient leurs épidermes. Le village où ils étaient avait un cimetière en plein centre de son espace. Les ceintures, la danse, I'enquête, la Baie des Chaleurs. Deux sculptures mortuaires jouèrent la tête et le pied de leur lit $d^{\prime}$ 'herbe. Prunelle s'accrocha, les hanches convulsives. Raviluc fouilla son regard, il aimait la voir le regardant pendant qu'elle I'appelait, pendant qu'ils s'acceptaient, pendant qu'il veillait le plus tard possible en elle... Les ceintures, les trouvailles, les yeux pleins d'étoiles, la voie lactée. Longtemps, ils abusèrent de la marée montante dans leurs veines, ils fêtèrent le mois de mai dans la rosée nocturne jusqu'à l'eau des aisselles. "Their world was going crazy in that anglican cemetary, crazy about themselves". Nuit blanche au cimetière phosphorescent, des nouveaux dieux sur des croix électriques. Crazy. Puis quand la femme eut pris toute la chaleur du monde dans ses membres et quand I'homme eut rendu l'écume à la mer, la marée descendit d'elle-même dans leurs yeux.

Prunelle, en boule, retenait les atmosphères de son corps. Adossé à la tête granitique du lit, Raviluc retrouvait à pleins poumons I'air tranquille de la nuit. II remarqua que l'enseigne au néon du "Coq tendre" animait par à-coups les vitraux de I'Anglican Church. II reprit la main de Prunelle. Son autre main frôlait I'herbe humide. II arracha le gazon jusqu'à la terre, creusa la terre de son majeur. La lune versa sa lumière fluide dans le trou.

Des dizaines de squelettes centenaires dormaient les phalanges flottantes entre les fémurs. Le Requiem de Chérubini 
traversa sa mémoire en voix mâles et la chorale folle impressionna ses nerfs dénoués. Raviluc cueillit une poignée de terre rouge, de terre étrangère, anglaise, anglicane et pleine de poudre d'os. II la lança dans I'air de la Gaspésie de l'autre côté de la clôture de fer forgé.

Raviluc allongea ses jambes, se mit à l'aise entre les deux sculptures funéraires, il était amoureux de Prunelle, sommeilleuse. II se sentait aérien et I'Anglican Church lui parut plus petite. II geignit d'agrément. La nuit parlait au diable... 